\title{
Structure and magnetic properties of hexagonal barium ferrite films deposited by alternate layer deposition method
}

\author{
H. Shimizu ${ }^{1}$, H. Shinozaki ${ }^{2}$, Y. Hoshi ${ }^{2}$, K. Kato ${ }^{1}$ and F. Kaneko ${ }^{3}$ \\ 1) Graduate School of Science and Technology, Niigata University \\ Ikarashi 2-8050, Niigata 950-21 Japan \\ 2) Department of Electronic Engineering, Tokyo Institute of Polytechnics, \\ 1583 liyama, Atugi, Kanagawa 243-02 Japan. \\ 3) Department of Electrical and Electronic Engineering, Niigata University \\ Ikarashi 2-8050, Niigata 950-21 Japan
}

\begin{abstract}
Deposition of c-axis perpendicularly oriented hexagonal barium ferrite thin films were formed by an alternate periodic deposition of $S\left(\mathrm{Fe}_{6} \mathrm{O}_{8}\right)$ and $R\left(\mathrm{BaFe}_{6} \mathrm{O}_{11}\right)$ layers. BaM film with excellent $c$-axis orientation and good crystallinity was obtained when $S$ layers $4.7 \ddot{A}$ thick and $R$ layers $6.9 \ddot{A}$ thick was deposited on a $\mathrm{ZnO}$ underlayer. To reduce the amount of the $\mathrm{Zn}$ ions diffusing from the $\mathrm{ZnO}$ underlayer to the BaM film, the thickness of the $\mathrm{ZnO}$ underlayer was reduced. An underlayer less than $10 \mathrm{~nm}$ thick, however, significantly degraded the c-axis orientation of the BaM films. We also tried to deposit $\mathrm{BaM}$ films on various kinds of underlayers such as $\alpha-\mathrm{Fe}_{2} \mathrm{O}_{3}$ and amorphous barium ferrite (a-BaM). A BaM film with $c$-axis orientation was obtained only on a $\mathrm{ZnO}$ underlayer and an a-BaM/ZnO underlayer, although the $c$-axis of the BaM crystallites in the film deposited on a $\mathrm{ZnO}$ underlayer inclined about 2 degrees from the normal to the film surface.
\end{abstract}

Key words : hexagonal barium ferrite, $c$-axis orientation, alternate periodic deposition, underlayer

\section{I . INTRODUCTION}

A hexagonal barium ferrite thin film is promising candidate as a high-density magnetic recording medium because of its high anisotropy field, mechanical hardness, and chemical stability. In recent years, much effort has been concentrated on the c-axis textured growth of barium ferrite thin films. [1]-[4] In this study, a deposition of $c$ axis perpendicularly oriented hexagonal barium ferrite thin films was attempted by means of an alternate periodic deposition of $S\left(\mathrm{Fe}_{3} \mathrm{O}_{4}\right)$ and $R$ $\left(\mathrm{BaO} \cdot 3 \mathrm{Fe}_{2} \mathrm{O}_{3}\right)$ layers, since the hexagonal barium ferrite (BaM : $\mathrm{BaFe}_{12} \mathrm{O}_{19}$ ) has a periodic layered structure composed of $S$ blocks $\left(\mathrm{Fe}_{6} \mathrm{O}_{8}\right)$ and $R$ blocks $\left(\mathrm{BaFe}_{6} \mathrm{O}_{11}\right)$ alternating in the $c$-axis direction. A BaM film with excellent $c$-axis orientation was obtained by alternately depositing $S$ layers $4.7 \AA$ thick and $R$ layers $6.9 \AA$ thick on a $\mathrm{ZnO}$ underlayer. We also attempted to reduced in the thickness of the $\mathrm{ZnO}$ underlayer and deposited
$\mathrm{BaM}$ films on various underlayers. such as $\alpha_{\mathrm{Fe}} \mathrm{O}_{3}$ and amorphous barium ferrite, in order to prevent the diffusion of $\mathrm{Zn}$ ions from the $\mathrm{ZnO}$ underlayer to BaM film. This paper describes in detail the structure of the BaM films deposited on $c$-axis oriented $\mathrm{ZnO}$ underlayers of various thickness and of the BaM films deposited on the various underlayers.

\section{EXPERIMENT}

Hexagonal barium ferrite thin films were deposited using a DC facing targets sputtering apparatus with three sputtering sources (for the deposition of the $\mathrm{ZnO}$ underlayer, the $\mathrm{S}$ layer, and the $R$ layer) shown in Fig. 1. The various underlayers - such as $\mathrm{ZnO}, \quad \alpha-\mathrm{Fe}_{2} \mathrm{O}_{3}$, amorphous $\mathrm{BaFe}_{6} \mathrm{O}_{10}$ (a- $\left.\mathrm{BaFe}_{6} \mathrm{O}_{10}\right)$ and amorphous barium ferrite (a-BaM) thin film - were first deposited on a thermally oxidized silicon wafer substrate. Then $S$ layers $4.7 \AA$ thick and $R$ layers $6.9 \AA$ thick were alternately deposited at $580^{\circ} \mathrm{C}$ under an ambient atmosphere consisting of $10 \% \mathrm{O}_{2}$ and $90 \% \mathrm{Ar}$. The deposited barium ferrite films were about $1150 \AA$ thick, and a typical deposition condition for the underlayer and the BaM film are listed in Tables I and II.

The crystal structure of the films was investigated by $\mathrm{x}$-ray diffraction, and the magnetic properties of the films were measured by using a vilbrating sample magnetometer (VSM).

\section{RESULTS AND DISCUSSION}

Figure 2 shows a typical $x$-ray diffraction diagram for a film obtained by the alternate deposition of Slayers $4.7 \AA$ thick and $R$ layers $6.9 \AA$ thick on a $c$-axis-orientated $\mathrm{ZnO}$ underlayer $15 \mathrm{~nm}$ thick. It should be noted that the diffraction peaks from the BaM (004) and $(0012)$ planes are clearly evident. This indicates that the BaM film 


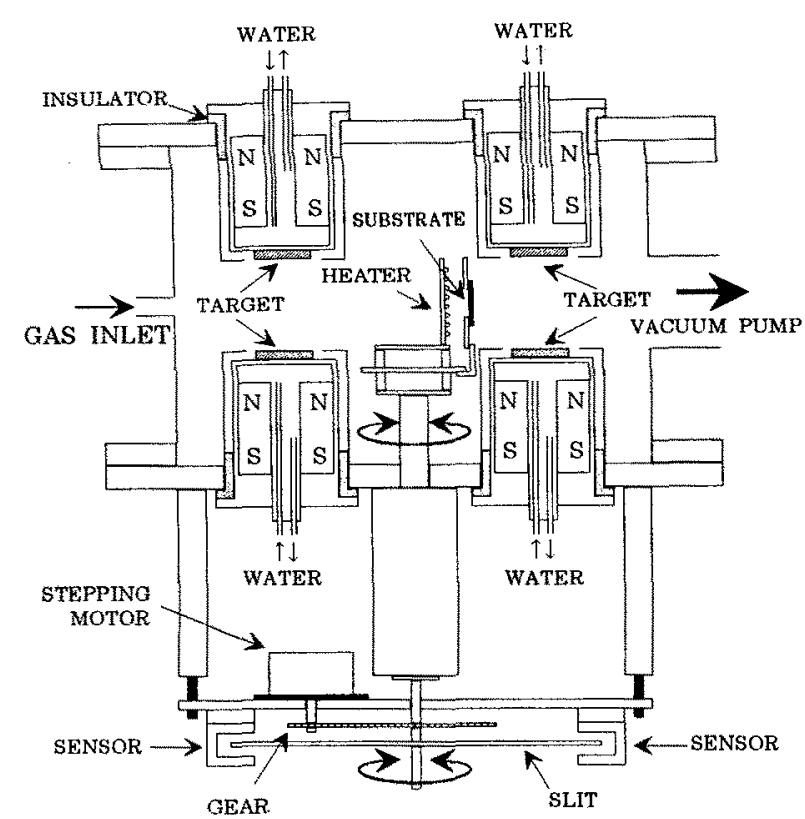

Fig. 1. Sputtering system used for film preparation.

Table I . Underlayer preparation conditions.

\begin{tabular}{|c|c|c|c|c|}
\hline underlayur & $\begin{array}{r}\begin{array}{r}\text { Sputtering } \\
\text { gas }\end{array} \\
\end{array}$ & $\begin{array}{l}\text { Gas } \\
\text { pressure }\end{array}$ & $\begin{array}{l}\text { Substrate } \\
\text { temperature }\end{array}$ & thickness \\
\hline $\mathrm{ZnO}$ & $20 \% \mathrm{O}_{2}+\mathrm{Ar}$ & 5 mTorr & $250^{\circ} \mathrm{C}$ & $\sim 15 \mathrm{~nm}$ \\
\hline$\alpha-\mathrm{Fe}_{2} \mathrm{O}_{3}$ & \multirow{4}{*}{$10 \% \mathrm{O}_{2}+\mathrm{Ar}$} & \multirow{4}{*}{3 mTorr } & \multirow{4}{*}{$200^{\circ} \mathrm{C}$} & $16 \mathrm{~nm}$ \\
\hline $\mathrm{a}-\mathrm{BaFe}_{6} \mathrm{O}_{10}$ & & & & $15 \mathrm{~nm}$ \\
\hline $\mathrm{a}-\mathrm{BaM}$ & & & & $23 \mathrm{~nm}$ \\
\hline a-BaM/ & & & & $23 \mathrm{~nm}$ \\
\hline $\mathrm{ZnO}$ & $20 \% \mathrm{O}_{2}+\mathrm{Ar}$ & 5 inTorr & $250^{\circ} \mathrm{C}$ & $15 \mathrm{~nm}$ \\
\hline
\end{tabular}

Table II . BaM film preparation condition.

\begin{tabular}{|c|c|c|}
\hline & $\begin{array}{c}\mathrm{BaO} \cdot 3 \mathrm{Fe}_{2} \mathrm{O}_{3} \\
\text { layer }\end{array}$ & $\begin{array}{c}\mathrm{Fe}_{3} \mathrm{O}_{4} \\
\text { Slayer }\end{array}$ \\
\hline Target & $\mathrm{BaO}^{2} 3 \mathrm{Fe}_{2} \mathrm{O}_{3}$ & $\mathrm{Fe} \mathrm{O}_{4}$ \\
\hline Substrate & \multicolumn{2}{|c|}{$\mathrm{ZnO} / \mathrm{SiO}_{2} / \mathrm{Si}$} \\
\hline Sputtering gas & \multicolumn{2}{|c|}{$30 \% \mathrm{O}_{2}+90 \% \mathrm{Ar}$} \\
\hline Gas pressure & \multicolumn{2}{|c|}{$580^{\circ} \mathrm{C}$} \\
\hline $\begin{array}{c}\text { Substrate } \\
\text { temperature }\end{array}$ & \multicolumn{2}{|c|}{$600-700 \mathrm{~V}$} \\
\hline Target voltage & $500-600 \mathrm{~V}$ & $50 \mathrm{~mA}$ \\
\hline Discharge current & $57 \mathrm{~mA}$ & $4.6 \AA$ \\
\hline Deposition cycles & \multicolumn{2}{|c|}{100} \\
\hline Thickness of layer & $6.9 \AA$ & 4 \\
\hline
\end{tabular}

has excellent $c$-axis orientation and good crystallinty. The saturation magnetization of this film, however, was only about $250 \mathrm{emu} / \mathrm{cc}$, much smaller than that of bulk BaM. This small value of the saturation magnetization seemed to be caused by the formation of $\mathrm{ZnFe}_{2} \mathrm{O}_{4}$ in the film, since diffraction peaks from $\mathrm{ZnFe}_{2} \mathrm{O}_{4}$ (111) plane are

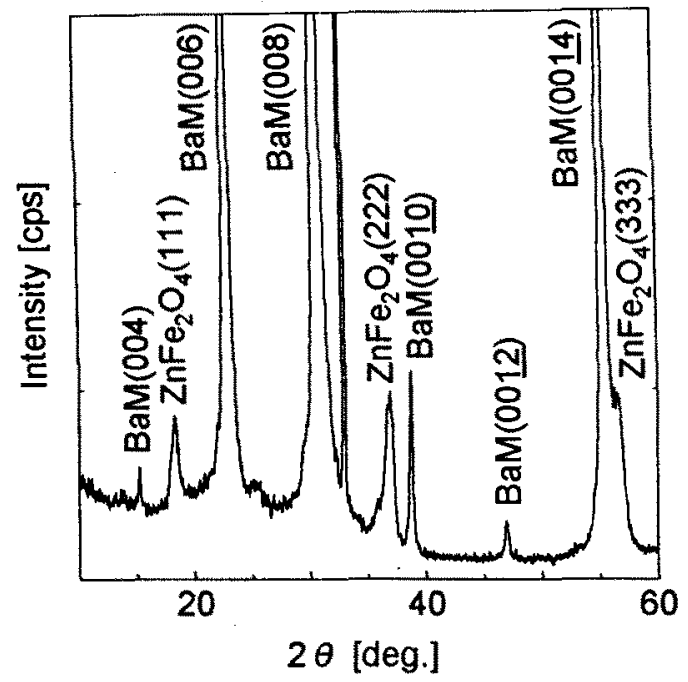

Fig. 2. X-ray diffraction diagram of a film with $S$ layers $4.7 \AA$ thick and $R$ layers $6.9 \AA$ thick, deposited on a $c$ axis-orientated $\mathrm{ZnO}$ underlayer of $15 \mathrm{~nm}$ thick.

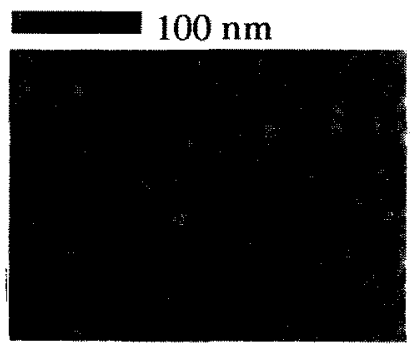

(a) as deposited

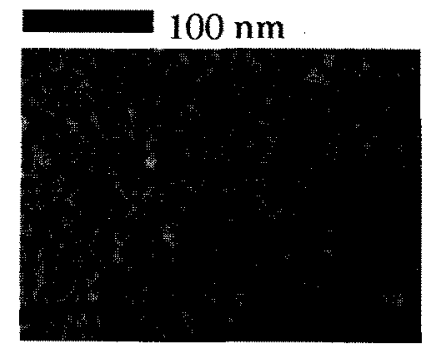

(b) annealed at $580^{\circ} \mathrm{C}$
Fig. 3. SEM surface micrographs of a $\mathrm{ZnO}$ underlayer 100 A thick.

also clear in the diffraction diagram. This $\mathrm{ZnFe}_{2} \mathrm{O}_{4}$ is thought to be formed by the diffusion of $\mathrm{Zn}$ ions from the $\mathrm{ZnO}$ underlayer into the BaM film. [4],[5]

To reduce the amount of the $\mathrm{ZnFe}_{2} \mathrm{O}_{4}$ in the film, we tried using a thinner $\mathrm{ZnO}$ underlayer. Figure 3 shows SEM surface micrographs of a $\mathrm{ZnO}$ underlayer $100 \AA$ thick. A continuous $\mathrm{ZnO}$ underlayer with $c$-axis orientation was also obtained at a thickness below $100 \AA$. BaM films were deposited on $\mathrm{ZnO}$ underlayers less than 150 $\AA$ thick, and Fig. 4 shows $x$-ray diffraction diagrams of those films. It is clear that when the thickness of the $\mathrm{ZnO}$ underlayer decreases below $100 \AA$, the diffraction peaks from the $c$-plane of the $\mathrm{BaM}$ become small and the diffraction peak from the BaM (107) plane become large. These results suggest that a decrease in the thickness of the $\mathrm{ZnO}$ underlayer below $100 \AA$ leads to a significant degradation of the $c$-axis orientation of the film. To obtain a BaM film with $c$-axis orientation, we 
should therefore use a $\mathrm{ZnO}$ underlayer more than $150 \AA$ thick.

Figure 5 shows $x$-ray diffraction diagrams of BaM films deposited on various kinds of underlayers. A BaM film with (001) texture was obtained only on $\mathrm{ZnO}$ and a-BaM/ZnO underlayers. The BaM films deposited on the $\alpha-\mathrm{Fe}_{2} \mathrm{O}_{3}$, a$\mathrm{BaFe}_{6} \mathrm{O}_{10}$, and a-BaM underlayers have diffraction peak from the BaM (107) plane. X-ray diffraction diagrams of these underlayers are shown in Fig. 6. The $\alpha-\mathrm{Fe}_{2} \mathrm{O}_{3}$ underlayer has a random orientation, which may result in the formation of a BaM film with random orientation. The a- $\mathrm{BaFe}_{6} \mathrm{O}_{10}$, a-BaM, and a-BaM/ZnO underlayers appear to have amorphous structure, since they have no clear diffraction peaks. Unlike the diffraction diagram of the BaM film cleposited on a-BaM underlayer, the diffraction diagram of the BaM film deposited on a-BaM/ZnO underlayer did not have a diffraction peak from (107) peak. This result suggests that the surface structure of an a-BaM film deposited on a $\mathrm{ZnO}$ underlayer differs from that of an a-BaM film dejosited on a $\mathrm{SiO}_{2} / \mathrm{Si}$ substrate.

Figure 7 shows, for BaM films deposited on various underlayers, the rocking curves of the BaM (008) diffraction peak and the full width at half-maximum values of the rocking curve $\left(\Delta \theta{ }_{50}\right)$. The shape and width of rocking curve depend on the kind of underlayer. The rocking curve of the BaM film deposited on a $\mathrm{ZnO}$ underlayer has two peaks indicating that the $c$-axis of the BaM crystallites in the film tilts about 2 from normal to the substrate surface. The film deposited at a high temperature on a $\mathrm{ZnO}$ underlayer has a normal rocking curve with one peak. The mechanism of the growth of the tilted crystallites on the $\mathrm{ZnO}$ underlayer is still unclear.

The magnetic properties of the BaM films deposited on the various underlayers are listed in Table III. Since the amorphous BaM film is not crystallized at a temperature below $700{ }^{\circ} \mathrm{C}$, diffusion of $\mathrm{Zn}$ ions from the $\mathrm{ZnO}$ underlayer to the BaM film is expected to be suppressed when the film is deposited on a-BaM/ZnO underlayer. The film deposited on $\alpha-\mathrm{Fe}_{2} \mathrm{O}_{3}$ underlayer has a very small $M_{s}(160 \mathrm{emu} / \mathrm{cc})$ and very small $H_{c / /}(0.15 \mathrm{Oe})$, perhaps because of poor erystallinity of the BaM film. A clear increase in saturation magnetization, however, was not observed when the BaM film was deposited on a a-BaM or a-BaM/ZnO underlayer, although the coercivity in the perpendicular direction $H_{c}+$ increased considerably. This increase in $H_{c_{\perp}}$ may be caused by the suppression of the diffusion of $\% / n$ ions.

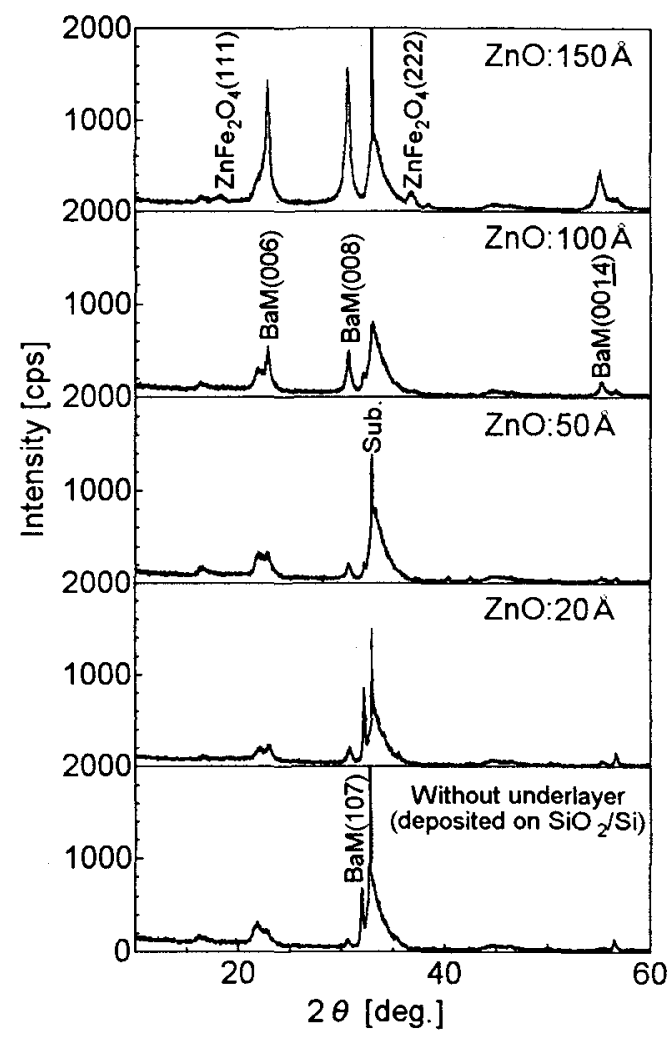

Fig. 4. X-ray diffraction diagrams of the films deposited on $\mathrm{ZnO}$ underlayers less than $150 \mathrm{~A}$ thick.

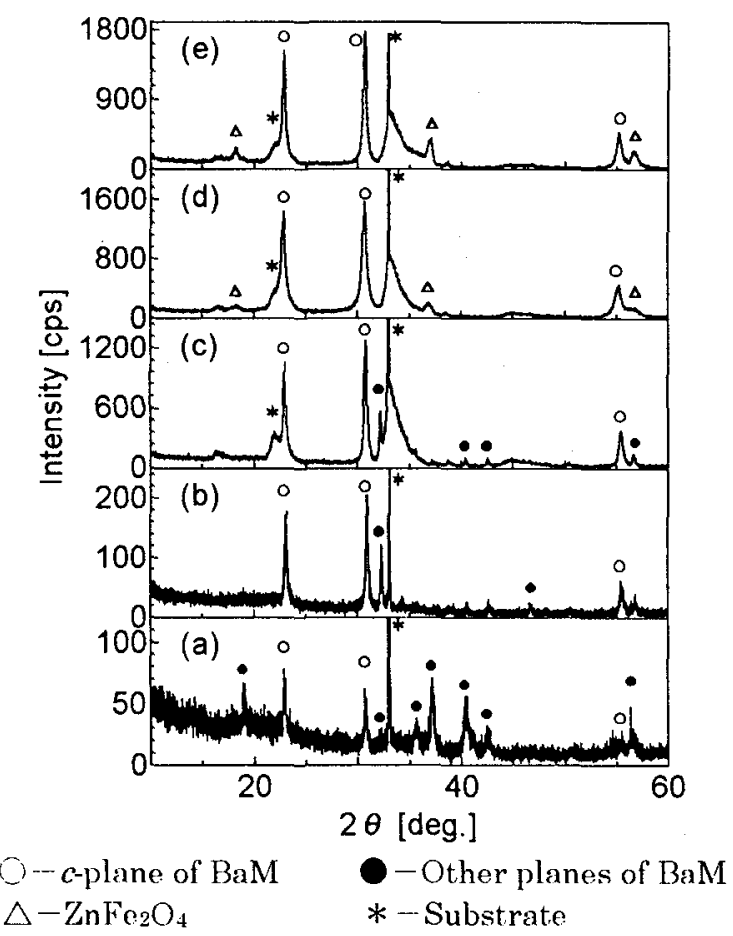

Fig. 5. X-ray diffraction diagrams of BaM films deposited on various underlayers : (a) on $\alpha-\mathrm{FegO}_{3}$ (b) on a-BaM (c) on a-BaFeoOro (d) on $\mathrm{ZnO}$ (e) on a$\mathrm{BaM} / \mathrm{ZnO}$ 


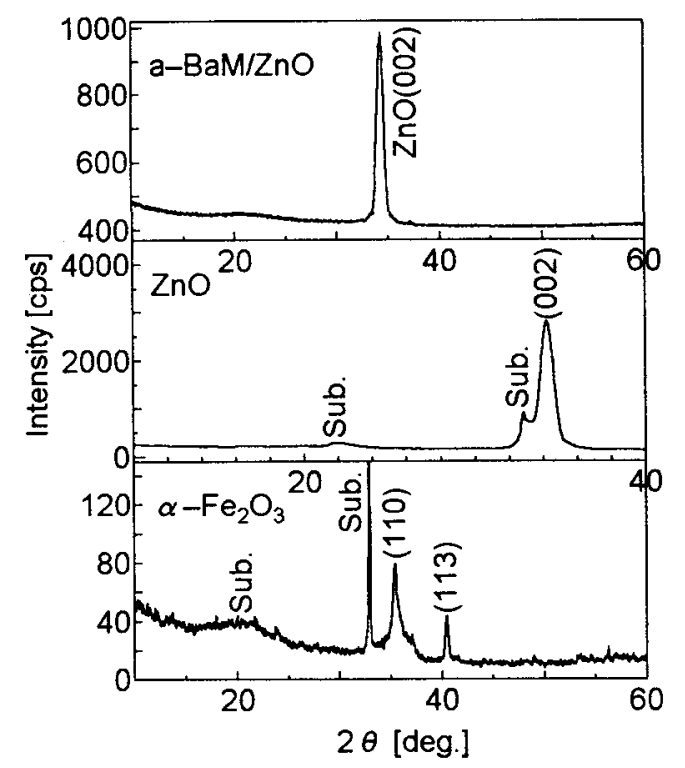

Fig. 6. X-ray diffraction diagrams of $\alpha-\mathrm{Fe}_{2} \mathrm{O}_{3}, \mathrm{ZnO}$, and a-BaM $/ \mathrm{ZnO}$ underlayers

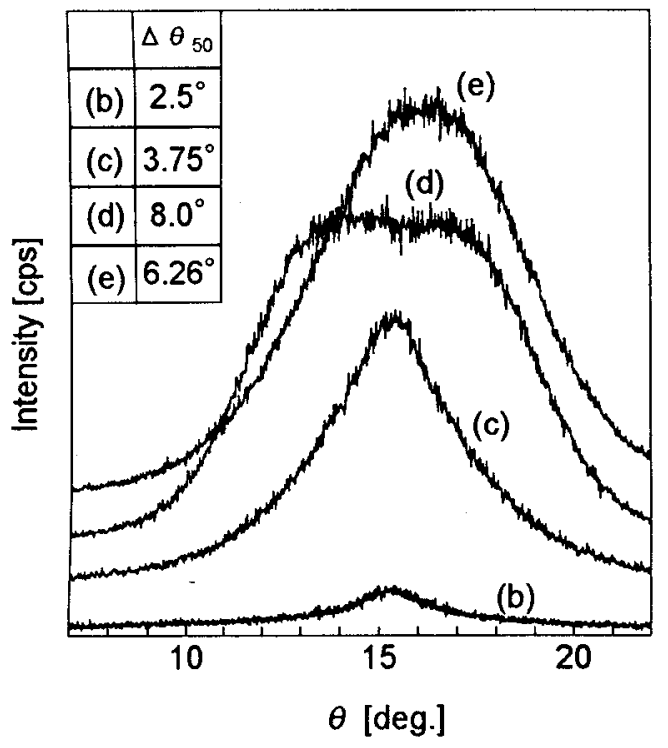

Fig. 7. Rocking curves of the BaM (008) diffraction peak and the full widths at half-maximum values for these curves $\left(\Delta \theta_{50}\right)$ when the BaM films were deposited on various underlayers : (b) on a-BaM (c) on a-BaFe. $\mathrm{O}_{10}(\mathrm{~d})$ on $\mathrm{ZnO}(\mathrm{e})$ on a-BaM/ZnO

Table III . Magnetic properties of BaM films deposited on the various underlayers.

\begin{tabular}{|c|c|c|c|}
\hline & $\begin{array}{c}\mathrm{M}_{s} \\
{[\mathrm{emu} / \mathrm{cc}]}\end{array}$ & $\begin{array}{c}\mathrm{H}_{\mathrm{c}} \\
{[\mathrm{kOe}]}\end{array}$ & $\begin{array}{c}\mathrm{H}_{\mathrm{c}} \\
\text { [kOe] }\end{array}$ \\
\hline \hline $\mathrm{Fe}_{2} \mathrm{O}_{3}$ & 160 & 1.86 & 0.15 \\
\hline $\mathrm{a}-\mathrm{BaM}_{\mathrm{a} O}$ & 215 & 4.50 & 3.55 \\
\hline $\mathrm{a}-\mathrm{BaFe}_{6} \mathrm{O}_{10}$ & 255 & 4.78 & 3.49 \\
\hline $\mathrm{ZnO}$ & 238 & 1.60 & 0.24 \\
\hline $\mathrm{a}-\mathrm{BaM} / \mathrm{ZnO}$ & 206 & 2.73 & 0.69 \\
\hline
\end{tabular}

\section{CONCLUUSIONS}

A $c$-axis perpendicularly oriented hexagonal barium ferrite thin films were deposited on various underlayers by using an alternate periodic layer deposition technique, and the following results were obtained :

(1) $\mathrm{A} \mathrm{ZnO}$ underlayer more than $150 \AA$ should be used in order to obtain a BaM film with $c$-axis orientation.

(2) The $c$-axis of the crystallites in the BaM films deposited on a $\mathrm{ZnO}$ underlayer is tilted about $2^{\circ}$ from the normal to the substrate surface.

(3) Suppressing of the diffusion of $\mathrm{Zn}$ ions from $\mathrm{ZnO}$ underlayer to BaM film by using an amorphous BaM intermediate layer leads to a considerable increase in coercivety of the film but does not increase the saturation magnetization.

\section{REFERENCES}

[1] A. Morisako, M. Matsumoto and M. Naoe, J.Magn. Soc. Jpn., vol.15, Suppl., No.S2, 401 (1991)

[2] N. Matushita, K. Noma and M. Naoe, IEEE Trans. Magn., 30, 4053 (1994)

[3]B. Y. Wong, X. Sui, D. E. Laughlin and M. H. Kryder, J. Appl. Phys., 75, 5966 (1994)

[4]J. Li, R. Sinclair, S. S. Rosenblum and H. Hayashi, J. Mater. Res., vol. 10, No.9, 2343 (1995)

[5]Y. Hoshi, Y. kubota, H. Onodera, H. Shinozaki, H. Shimizu, H. Ikawa J. Appl. Phys., 81 [8], 15, April, 4690 (1997) 